Masuma H. Mammadova1, Faig R. Mammadzada ${ }^{2}$

Institute of Information Technology of ANAS, Baku, Azerbaijan

${ }^{1}$ masuma.huseyn@iit.ab.az, ${ }^{2}$ faig.mammadzada@idrak.az

\title{
DEVELOPMENT OF THE TECHNIQUE OF ASSESSING THE TOTAL NUMBER OF IT PROFESSIONALS IN AZERBAIJAN
}

The current state of Azerbaijan's labor market IT-segment is analyzed from the position of its provision with human resources. The method of calculating the IT specialists number by economic activity kinds, based on expert-statistical estimates, are developed. Calculations of total number of IT specialists, employed in the economy of Azerbaijan, the specific weights of IT specialists in the ICT sector and other sectors of the national economy are carried out.

Keywords: IT segment, labor market, quantitative assessment of human resources, the concept of the formation of IT specialists need, heuristic algorithm for calculating of IT specialists number.

\section{Introduction}

In recent years, there has been a rapid growth of the macroeconomic importance of ICT as a catalyst for the effective functioning of not only certain spheres of human activity, but also the socioeconomic development of countries as a whole. This, in turn, leads to an ever-growing expansion in the demand for IT professionals in various fields of the national economies and requires the application of new approaches to the management of IT labor market $[1,2]$.

In practice, IT labor market is managed only through a real representation of its state of art. In this regard, it is necessary to investigate the IT segment of the labor market in the context of an individual country, using all possible information sources characterizing the main parameters of this object from various aspects, which in turn implies:

1) analysis of the current state of the IT-segment of the labor market from the perspective of demand, i.e., provision of human resources;

2) analysis of the current state of the IT-profile education market as the main source of demand for IT specialists;

3) joint research of supply and demand in the IT-segment of the labor market and assessment of the level of satisfaction with the demand for IT specialists by the IT-profile education system.

The obtained information will reveal the real demand-supply ratio for IT specialists in Azerbaijan, draw conclusions regarding the balance between the IT-segment of the labor market and IT-profile education, and develop well-grounded decisions on bringing the system of training IT personnel in line with the requirements of the country's economy.

\section{Approaches to the assessment of the total number of human resources in IT sector}

According to the world practice, when assessing the human resources employed in the economy, two sections are taken into account: sectoral and professional [3, 4]. In the context of the IT-segment of the labor market, the sectoral context includes all IT professionals working only in the ICT sector, including the administrative and support staff of organizations in this sector. From the standpoint of the professional section, today, IT professionals are working in any sector of the economy and their number in all its branches should be taken into account when assessing the professional labor market. This approach provides a holistic picture in the IT-segment of the labor market, it enables to assess the need for IT specialists in the country more fully and accurately, and helps to increase the competence of managerial decisions (impacts) in the IT-profile education.

At present, most of the information sources provide a restricted definition of the professional aspect of the IT-segment of the labor market, and IT professionals engaged only in the IT industry are considered when assessing human resources. This is due to the absence of: 1) unified classification and unambiguous definition of IT professions and specialties in various data sources; 2) statistics in the context of specific IT professions and specialties; 3) practical methods for the 
assessment of the number of IT specialists by economic sectors.

According to [3], today in developed countries, more than half of IT professionals are working beyond this industry. The wider the field of IT introduction, the faster the number of IT professionals working beyond this sector grows. Thus, Eurostat reports that, in 2009, 45.5\% of IT professionals in Europe worked in the IT industry. Respectively, the prevailing part of IT specialists (54.5\%) worked in other sectors, i.e. in the user area. In 2013, 48\% of IT professionals in Europe worked in the ICT sector, whereas 52\% - beyond this sector [5]. In Russia, the survey conducted in 345 organizations of various sizes with a total of 187,338 employees and selfemployed IT professionals (freelancers) showed that $29 \%$ of all IT professionals were engaged in the IT sector, while $71 \%$ were employed in other industrial enterprises [6].

In the context of the above, it is crucial to solve the problem of assessing the number of IT specialists employed in the ICT sector and other sectors of the economy of Azerbaijan, or, as is customary in official statistics, by kinds of the economic activity (TEA). For today, 18 kinds of economic activity are specified in the national economy of Azerbaijan.

Accordingly, the object, subject matter and purpose of the study are determined.

The object of the study is the labor market of IT specialists in Azerbaijan.

The subject matter of the study is an analysis of the current state of the IT-segment of the labor market of Azerbaijan from the perspective of its provision with human resources.

The purpose of the study is to develop a method for assessing the total number of IT professionals employed in the economy of Azerbaijan.

Initial data. The State Statistics Committee (SSC) of the Republic of Azerbaijan provides information on the number of IT professionals only in the context of the ICT sector, which is one of the branches of the national economy with a corresponding field of activity and tasks assigned to it.

The lack of statistical data on the number of employees, the number of vacancies in the context of specific professions and specialties, including in the IT field, significantly complicates the analysis of the trends in the number and demand for IT professionals, and does not allow estimating their number in terms of certain kinds of economic activity.

At the same time, the SSC collects and processes a large number of indicators characterizing the level of development of the information society and ICT in Azerbaijan [7]. The statistical compilation "Information Society and Information and Communication Technologies in Azerbaijan" contains data on the ICT used by households and organizations, on the availability of ICT systems and Internet access, including the main macroeconomic indicators of the activities of the organizations of ICT sector, and the data on exports and import of goods and services, and so forth. Although none of these indicators directly provide information on staffing needs, but indirectly contain some data.

From our point of view, the selection of the most informative statistical indicators indirectly characterizing the demand for staffing, and the involvement of experts in their assessment may provide the information required for the calculation of the demand for IT professionals in the economic sectors.

The problem statement. Developing a practical method for the calculation of the number of IT professionals by kinds of economic activity and by their totality based on the expert and statistical estimates.

The problem solution for the calculation of the number of IT specialists employed in the economic sectors of Azerbaijan presumes the consistent implementation of the following heuristic algorithm:

Step 1.To identify the statistical indicators of ICT indirectly characterizing the demand for IT professionals.

Stage 2. To conduct an expert estimates of the impact of the selected indicators on the demand for IT professionals.

Step 3. To calculate the number of IT professionals by the generated scenarios in terms of the kind of economic activity (excluding IT professionals working in the ICT sector) taking into 
account the expert estimates.

Step 4. To calculate the number of IT professionals in the ICT sector in accordance with each scenario and compare the calculated data with the statistical values of respective indicator. To take the scenario performing the smallest deviation of the calculated value from the statistical one as the basis for estimating the number of IT specialists in foreign economic activity.

Stage 5. To calculate the total number of IT professionals in Azerbaijan, their share in the ICT sector and economic activities.

\section{Implementation of the method for the estimation of the number of IT specialists by kinds of economic activity}

Step 1. Selection of statistical indicators of ICT indirectly assessing the need for IT professionals.

The ICT data collected, processed and presented by the state statistical agencies as the statistical reporting are quite diverse.

In order to determine the number of IT specialists in terms of KEA, taking into account the forms of statistical reporting [7], we selected indicators that, from our point of view, indirectly characterize the demand for IT specialists and can be used to calculate their quantity:

1. $\mathrm{N}_{1}$ - number of organizations using computers.

2. $\mathrm{N}_{2}$ - number of organizations with the Internet access.

3. $\mathrm{N}_{3}$ - number of organizations having web-sites (Fig. 1).

4. $\mathrm{R}_{1}$ - distribution of organizations using ICT in terms of the number of employees.

5. $\mathrm{R}_{2}$ - distribution of organizations with the Internet access in terms of the number of employees.

6. $\mathrm{U}_{1}$ - proportion of organizations with ICT infrastructure (\% of the number of all surveyed organizations of the given kind of activity).

7. $\mathrm{U}_{2}$ - proportion of organizations using computers (\% of the number of all organizations operating in Azerbaijan).

8. $\mathrm{U}_{3}$ - proportion of organizations using different kinds of networks (wireless and wired LAN, Intranet, Extranet).

9. $\mathrm{P}_{1}$ - number of employees using computers (fig.2).

10. $\mathrm{P}_{2}$ - number of employees using computers and having the Internet access (fig.2).

A lot of indicators are open and can be supplemented with more complete information. Figures 1-2 clearly illustrate the statistical data on the ICT infrastructure of organizations in the context of KEA.

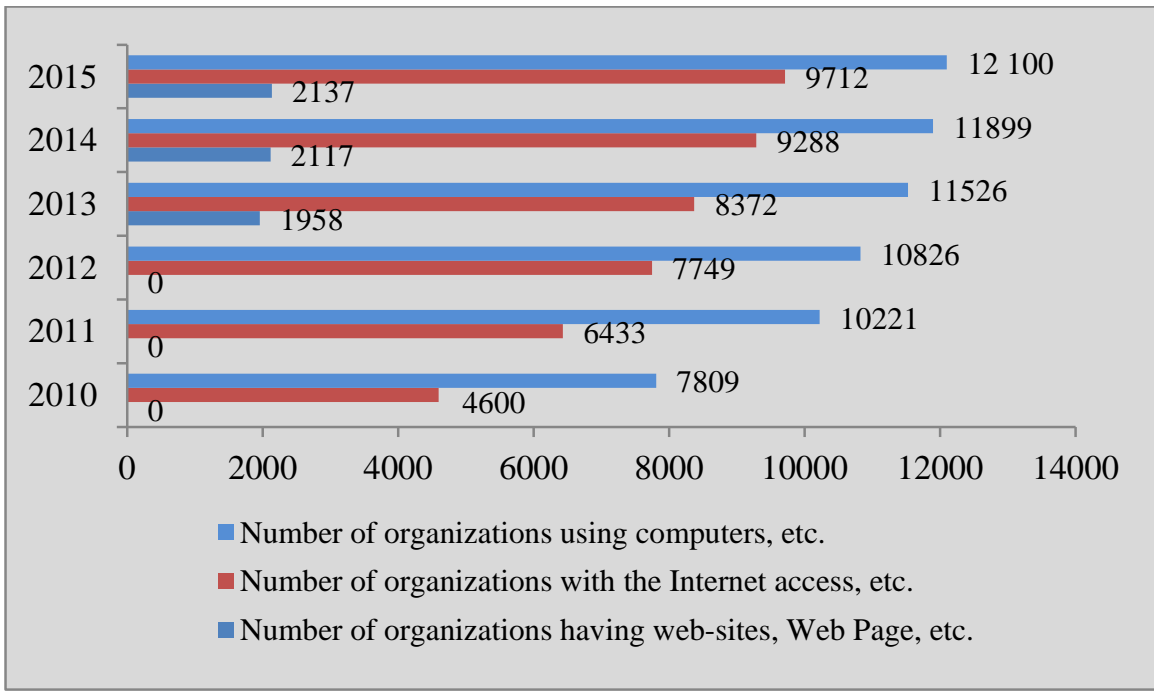

Fig. 1. The number of organizations with ICT infrastructure 


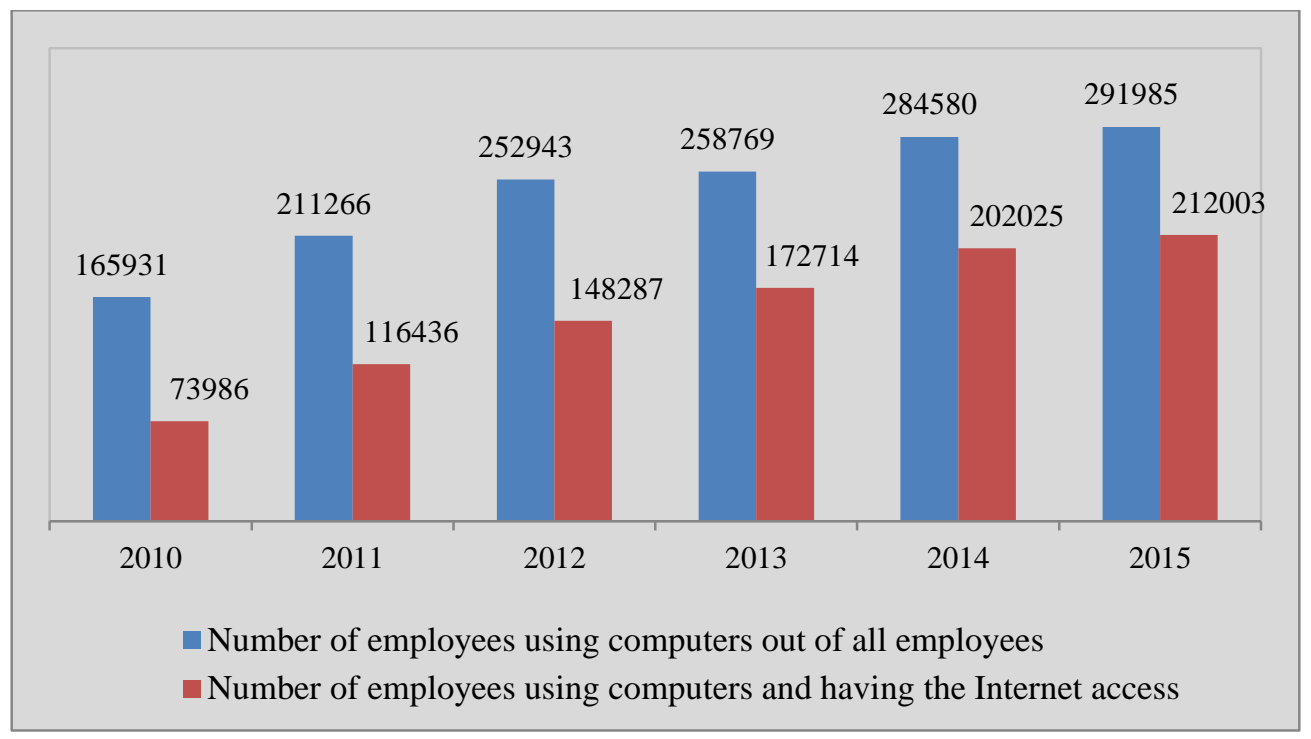

Fig. 2. The number of employees using computers and having the Internet access

In [7], it is provided the distribution of organizations with ICT infrastructure by the number of employees. At the same time, a number of interval groupings are distinguished, the boundaries of which present the minimum and maximum number of employees in the organization. Thus, the organizations depending on the number of employees have the following distribution: 1) 1-4 employees; 2) 5-9 employees; 3) 10-49 employees; 4) 50-249 employees; 5) 250 or more employees. Depending on the number of employees, this allows to classify the organizations by their size and quantity into microenterprises $\left(\mathrm{n}_{\text {micro }}\right)$ with $1-4$ employees; mini-enterprises $\left(\mathrm{n}_{\text {mini }}\right)$ with 5-9 employees; small enterprises $\left(\mathrm{n}_{\text {small }}\right)$ with 10-49 employees; medium-sized enterprises $\left(\mathrm{n}_{\text {medium }}\right)$ with 50-249 employees; large enterprises $\left(\mathrm{n}_{\text {large }}\right)$ with 250 employees or more.

We develop a conceptual framework for the formation of a quantitative demand for IT specialists at the country (Azerbaijan) level depending on the kinds of economic activity, the number of organizations in KEA and their scale, which is provided in Fig.3. As can be seen from the scheme, in general, the national economy of Azerbaijan is represented as a combination of different sectors. The total number of enterprises by all KEA can be determined based on the data available at the time $t$ about the number of different sized enterprises with IT infrastructure.

Let $A=\left\{A_{1}, A_{2}, \ldots, A_{m}\right\}=\left\{A_{i}, i=\overline{1, m} ; m=18\right\}$ be a set of kinds of economic activity. Then the total number of different sized enterprises for all KEA is calculated as follows:

$$
N(t)_{K E A}=\sum_{i=1}^{m}\left(n(t)_{\text {imicro }}+n(t)_{i \min i}+n(t)_{i s m a l l}+n(t)_{\text {imedium }}+n(t)_{i \operatorname{larg} e}\right),
$$

where $\left\{A_{i}, i=\overline{1, m} ; m=18\right\}$ corresponds to the sequence of KEA, adopted in [7].

The methodology for the formation of a quantitative demand for IT professionals in accordance with the conceptual scheme is based on the statistical data on the number of organizations for each KEA using different ICT tools and services; interval of quantitative variation in the number of employees in the organizations that determine the size of the latter. The lack of statistical data on the number of specific professions and specialties, including of those employed in the ICT sector, necessitates an expert assessment of the demand for IT specialists in KEA.

Step 2. Conducting expert estimates of the impact of the selected indicators on the demand for IT professionals.

To implement this stage of the study, an expert survey is conducted based on the target statistics and aimed at identifying the demand for IT professionals depending on the size and ICT infrastructure of the enterprise. Highly qualified specialists of the Institute of Information 
Technology of ANAS are involved as the experts, the scientific and professional competence of whose represents the demand for IT specialists based on the data provided by them. Thus, the experts are asked to answer the question of the quantitative demand for IT professionals in the organization depending on its size (number of employees) and the kind of ICT infrastructure serviced. Since the values of the number of employed in different sized organizations vary within certain limits, i.e. are given in the form of closed interval scales, then, of course, expert estimates are also formed as the interval scales with the specification of the lower (minimum) and upper (maximum) boundaries of the demand for IT specialists.

Stage 3.The calculation of the number of IT specialists (in three scenarios) in terms of KEA, including the ICT sector taking into account the expert estimates.

Expert estimates allow compiling three scenarios, the corresponding to minimum, average and maximum values of the interval scale reflecting the needs of organizations in IT professionals for each kind of economic activity using statistics. This statistics is on the number of organizations using the ICT infrastructure, the grouping of employees by number of employees and the range of variations in the number of IT specialists required in them.

The number of micro- (1-4 employees) and mini- (5-9 employees) organizations by KEA for the period 2011-2015 is calculated by the formula as follows:

$$
N(t)_{K E A}^{n k 12}=\sum_{i=1}^{m}\left(n(t)_{\text {imicro }}+n(t)_{i \min i}\right)
$$

As follows from the arguments of the experts and their assessments, micro and mini enterprises using ICT can hardly have a staff of IT professionals. The results of labor market monitoring of IT specialists [8] also confirm this fact. According to the results, these enterprises are serviced mainly by freelancers, including the IT service providers. Therefore, in the present work, it is accepted that micro- and mini-organizations use the services of freelancers.

Next, the category of small enterprises, in which the number of IT professionals varies in [10-49], is considered. According to the expert assessments, depending on the proximity of the real number of employees of small organizations to the minimum or maximum limit of the interval for their maintenance, (1-3) IT specialists are required. In this case, the assessments of the parameter under consideration are given by the experts in the form of intervals, which seems to be a more regular assessment for this task. This kind of assessment combines quantitative and qualitative approaches. In accordance with this, the interval under study is also divided into a number of segments through the grouping method. These segments represent a diverse number of employees in the organizations with ICT infrastructure. The value of identical intervals is determined by the formula:

$$
i=\frac{X_{\max }-X_{\min }}{n}
$$

where, $i$-denotes the value of the variation interval of the number of employees; $X_{\min }, X_{\max }$ - the minimum and maximum boundaries of the variation interval of the number of employees, $(n=2$, $3, \ldots)$ - the number of segments.

This procedure allows us to generate various scenarios taking into account the interval expert evaluations for calculating IT professionals in small, medium and large organizations in accordance with fuzzy logic rules in the following form:

$$
\begin{gathered}
R_{1}: \text { If } \quad X_{\min } \leq x_{1}<X_{1} \text { then } y_{1}=B_{1} \\
R_{2}: \text { If } \quad X_{1} \leq x_{2}<X_{2} \text { then } y_{2}=B_{2} \\
\ldots \ldots \ldots \ldots \ldots \ldots \ldots \ldots \ldots \ldots \ldots \ldots \ldots \ldots \ldots \\
R_{n}: \text { If } X_{\mathrm{n}-1} \leq x_{\mathrm{n}} \leq X_{\max } \text { then } y_{\mathrm{n}}=B_{\mathrm{n}},
\end{gathered}
$$

where, the input data is fuzzy, and the output is non-fuzzy. 

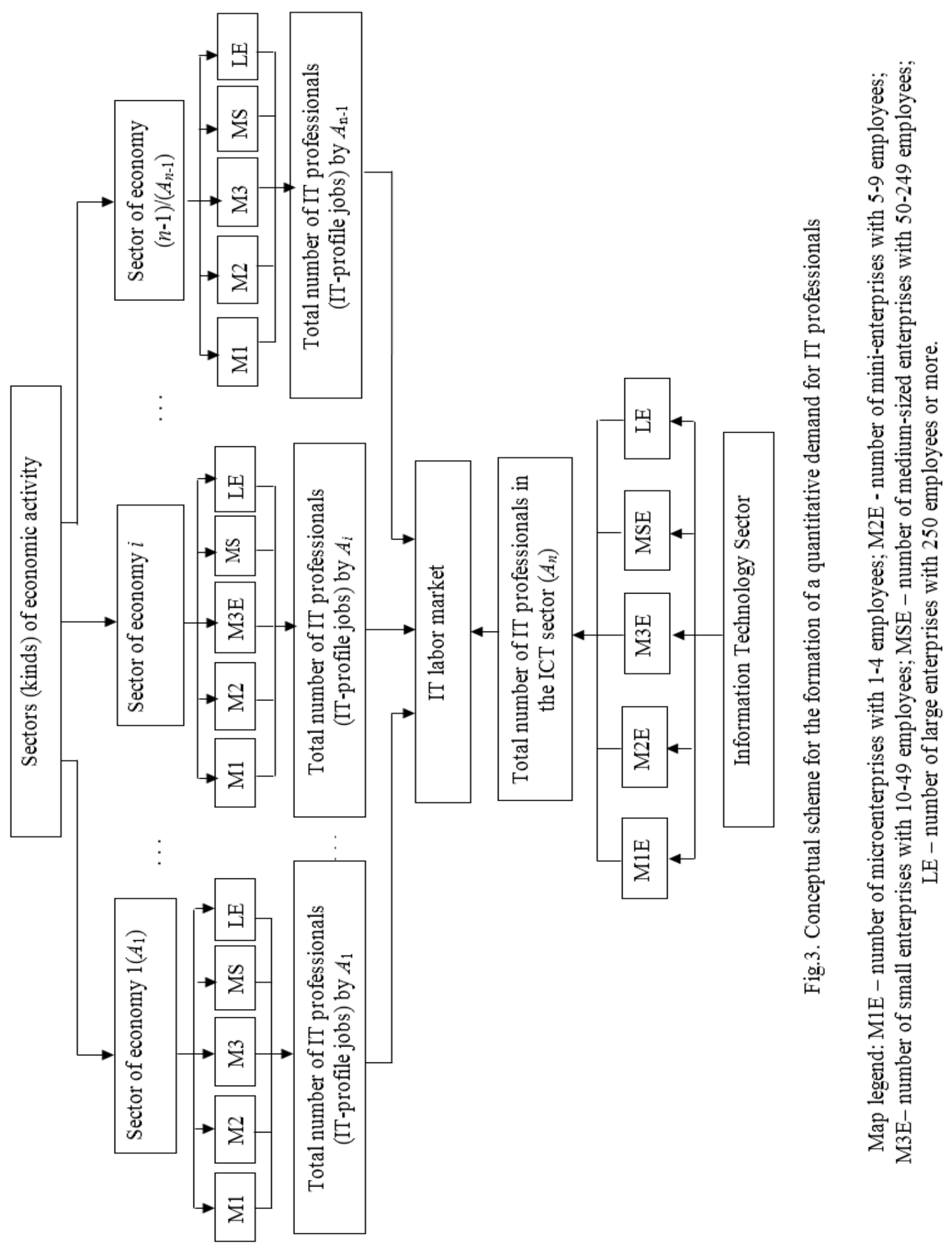
In this study, the calculations of the number of IT specialists in the sectorial organizations are implemented in three scenarios. The sequence of calculation is illustrated on the example of small organizations, in which the number of IT specialists varies within [10-49]. For a given kind of organization, the formula (3) accepts $n=3$ and has segments: [10-23), [23-36], [36-49] and the following rules:

$$
\text { if } 10 \leq x_{1}<23 \text { then } y_{1}=1 \text {; if } 23 \leq x_{2}<36 \text { then } y_{2}=2 \text {; if } 36 \leq x_{3} \leq 49 \text { then } y_{3}=3 \text {. }
$$

Furthermore, the number of small organizations by all KEA $A=\left\{A_{i}, i=\overline{1, m} ; m=18\right\}$ at time $t$ is defined by the following formula:

$$
N(t)_{K E A}^{\mathrm{M} 3 \mathrm{E}}=\sum_{i=1}^{m}\left(n(t)_{\text {ismall }}+n(t)_{\text {imedium }}+n(t)_{i l \text { arge }}\right)
$$

Table 1 shows the results of calculations of the number of IT professionals in small organizations by KEA for the period 2011-2015, which have ICT infrastructure. The number of employees in these enterprises varies within [10-49].

Table 1

The number of IT professionals in the sectorial organizations with ICT infrastructure and

10-49 employees (2011-2015) number of org. scenario prof.

\begin{tabular}{|c|c|c|c|c|}
\hline Years & $\begin{array}{c}\text { Number } \\
\text { of org. }\end{array}$ & $\begin{array}{c}\text { Scenario.1: 1IT- prof. } \\
\text { Number of IT- prof. }\end{array}$ & $\begin{array}{c}\text { Scenario.2: 2IT- prof. } \\
\text { Number of IT- prof. }\end{array}$ & $\begin{array}{c}\text { Scenario.3: 3IT- prof. } \\
\text { Number of IT- prof. }\end{array}$ \\
\hline 2011 & 3672 & 3672 & 7344 & 11016 \\
\hline 2012 & 3758 & 3758 & 7516 & 11274 \\
\hline 2013 & 3848 & 3848 & 7696 & 11544 \\
\hline 2014 & 4075 & 4075 & 8150 & 12225 \\
\hline 2015 & 4091 & 4091 & 8182 & 12273 \\
\hline
\end{tabular}

Table 2 illustrates the data on the number of IT professionals in the KEA organizations for the period 2011-2015, which have ICT infrastructure, and the number of employees in which varies within the interval 50-249.

Table 2

The number of IT professionals in the sectorial organizations with ICT infrastructure and 50-249 employees (2011-2015)

\begin{tabular}{|c|c|c|c|c|}
\hline Years & $\begin{array}{c}\text { Number of } \\
\text { org. }\end{array}$ & $\begin{array}{c}\text { Scenario.1: 3IT- prof. } \\
\text { Number of IT- prof. }\end{array}$ & $\begin{array}{c}\text { Scenario.2: 7IT- prof. } \\
\text { Number of IT- prof. }\end{array}$ & $\begin{array}{l}\text { Scenario.3: 10IT- prof. } \\
\text { Number of IT- prof. }\end{array}$ \\
\hline 2011 & 1845 & 5535 & 12915 & 18450 \\
\hline 2012 & 2168 & 6504 & 15176 & 21680 \\
\hline 2013 & 2501 & 7503 & 15256 (6 IT- prof.)* & 22509 (9 IT- prof.)* \\
\hline 2014 & 2185 & 6555 & 15295 & 21850 \\
\hline 2015 & 2222 & 6666 & 15554 & 22220 \\
\hline
\end{tabular}

\footnotetext{
* 2013 was declared the Year of ICT, which promoted the implementation of dynamic measures to introduce ICT in various sectors of the economic activity. As follows from the statistics, in 2013, a sharp increase in the number of medium-sized enterprises was observed, and in 2014, almost the same number of enterprises disappeared. To compensate for the short-term growth in demand for IT professionals in the second and third scenarios, the number of demanded IT specialists is less by one person.
} 
In accordance with the accepted classification, these are the medium organizations. It should be noted that the range of variation (difference between the maximum and minimum values of the boundaries of the interval) is quite large for medium-sized organizations, which is represented in the expert assessments. Thus, in accordance with the expert assessments, 3-10 IT specialists are required to service the ICT infrastructure of medium-sized organizations.

Similarly, IT specialists in medium-sized organizations are calculated in three scenarios. Table 3 shows the data on the number of IT professionals in the organizations of KEA using ICT for the period 2011-2015, in which the number of employees is 250 or more people.

Table 3

The number of IT professionals in the sectoral organizations with ICT infrastructure with 250 or more employees (2011-2015)

\begin{tabular}{|c|c|c|c|c|}
\hline Years & $\begin{array}{c}\text { Number } \\
\text { of org. }\end{array}$ & $\begin{array}{c}\text { Scenario.1: 10 IT- prof. } \\
\text { Number of IT- prof. }\end{array}$ & $\begin{array}{c}\text { Scenario.2: 15IT- prof. } \\
\text { Number of IT- prof. }\end{array}$ & $\begin{array}{l}\text { Scenario.3: 20IT- prof. } \\
\text { Number of IT- prof. }\end{array}$ \\
\hline 2011 & 541 & 5410 & 8115 & 10820 \\
\hline 2012 & 560 & 5600 & 8400 & 11200 \\
\hline 2013 & 710 & 7100 & 10650 & 14200 \\
\hline 2014 & 770 & 7700 & 11550 & 15400 \\
\hline 2015 & 809 & 8090 & 12135 & 16180 \\
\hline
\end{tabular}

In accordance with the adopted classification, these organizations are categorized as large. Since the maximum limit of the interval for the given kind of organization remains open, i.e., the statistic data is missing, it is difficult to evaluate the extent of the variation. We make an expert assessment of the possible number of organizations, which number varies from 250 to 500 . To this end, the specific weights of large organizations with a sufficiently developed IT infrastructure, including the distribution of enterprises and organizations registered in the State Register of Statistical Units on the number of employees. An analysis of these data reveals that the number of enterprises with 250-500 or more employees accounts for approximately $11-15 \%$ of the total number of large enterprises. For the maintenance of the ICT infrastructure of large organizations, the experts estimate that 10-20 IT specialists are required. Accordingly, in IT specialists of large organizations are evaluated in three scenarios in the same way. Using the calculation results of the number of IT specialists for various sized organizations (Tables 4.5-4.7), we find the total number of IT specialists in KEA, based on three scenarios using the following formula:

$$
\mathrm{P}^{j}(t)_{K E A}=P^{j}(t)_{\text {small }}+\mathrm{P}^{\mathrm{j}}(t)_{\text {medium }}+\mathrm{P}^{j}(t)_{\text {large }},
$$

where $2011 \leq t \leq 2015$; - Scenarios.

Table 4 shows the total number of IT professionals employed during 2011-2015 in the sectors of the economy, with the exception of those working in the field of ICT.

Table 4

The total number of IT professionals employed in the sectors of the economy excluding those working in the field of ICT (2011-2015)

\begin{tabular}{|c|c|c|c|}
\hline Years I & I option & II option & III option \\
\hline 2011 & 14617 & 28374 & 40286 \\
\hline 2012 & 15862 & 31092 & 44154 \\
\hline 2013 & 18451 & 33602 & 48253 \\
\hline 2014 & 18330 & 34995 & 49475 \\
\hline 2015 & 18847 & 35871 & 50673 \\
\hline
\end{tabular}


Step 4. The calculation of the number of IT professionals in the ICT sector, in accordance with each scenario, and the comparison of the calculated data with the statistical values of this indicator. The scenario performing the lowest deviation of the calculated value from the statistical one is taken as the basis for estimating the number of IT specialists in KEA.

To ensure the comparability of data representing the number of employees in the enterprises of both ICT sector and economic sectors, the official statistics on the number of enterprises in the ICT sector and their distribution by the number of employees and, respectively, by the size of the enterprise were obtained on the request of the SSC (Table 5). In accordance with the data provided in Table 5, the dynamics of the organizations of the ICT sector and their number shows a significant expansion of the ICT sector over 5 years, with the industry growing mainly at the expense of non-state organizations, i.e. the development of private entrepreneurship in this field. Undoubtedly, the rate of high growth of micro-organizations, where four or less people are employed, is also outlined. The number of this category has doubled for five years. Moreover, only two organizations out of 264 micro-organizations were state-owned in 2015.

Table 5

The total number of ICT sector enterprises and their distribution by the number of employees

(2011-2015)

\begin{tabular}{|c|c|c|c|c|c|c|c|}
\hline \multirow{2}{*}{$\begin{array}{l}\text { Distribution of the total } \\
\text { number of ICT sector } \\
\text { enterprises by the number of } \\
\text { employees }\end{array}$} & \multirow[t]{2}{*}{2011} & \multirow[t]{2}{*}{2012} & \multirow[t]{2}{*}{2013} & \multirow[t]{2}{*}{2014} & \multirow[t]{2}{*}{2015} & \multicolumn{2}{|c|}{$\begin{array}{c}\text { Distribution of the } \\
\text { ICT sector enterprises } \\
\text { by ownership, } \mathbf{2 0 1 5}\end{array}$} \\
\hline & & & & & & state & non-state \\
\hline $\begin{array}{l}\text { Total number of enterprises } \\
\text { in the ICT sector }\end{array}$ & 346 & 384 & 422 & 493 & 528 & 100 & 428 \\
\hline $\begin{array}{l}\text { Number of enterprises with } \\
1-4 \text { employees }\end{array}$ & 127 & 150 & 168 & 221 & 264 & 2 & 262 \\
\hline $\begin{array}{l}\text { Number of enterprises with } \\
5-9 \text { employees }\end{array}$ & 46 & 61 & 70 & 69 & 67 & 5 & 62 \\
\hline $\begin{array}{l}\text { Number of enterprises with } \\
10-49 \text { employees }\end{array}$ & 81 & 79 & 88 & 106 & 105 & 23 & 82 \\
\hline $\begin{array}{l}\text { Number of enterprises with } \\
50-249 \text { employees }\end{array}$ & 77 & 79 & 81 & 82 & 78 & 59 & 19 \\
\hline $\begin{array}{l}\text { Number of enterprises with } \\
250 \text { or more employees }\end{array}$ & 15 & 15 & 15 & 15 & 14 & 11 & 3 \\
\hline
\end{tabular}

Using the data provided in Table 5 and the expert assessments, in three scenarios, the number of IT specialists were calculated. The fundamental difference at this stage, such as setting the task of assessing the number of IT professionals, and the compilation of scenarios should also be mentioned. Thus, the identification of the demand for IT staff by industry is based on an expert assessment of the number of IT professionals in the KEA organizations, which should provide the IT infrastructure of the organization. In this case, the number of IT professionals employed in KEA is unknown. Therefore, to identify the demand for IT professionals, the industrial organizations use indirect indicators, expert assessments and scenarios. When it comes to the number of IT professionals in the ICT sector, the SSC provides information on the number of employees in the ICT sector (Table 6). At the same time, the proportion of those who are not employed in the core activity can also be calculated based on the data about the number of employees in the ICT sector, both in terms of the core activity profile (IT specialists) and non-core activity profile. 
The objective of the task is to obtain the estimated data on the number of IT professionals in the ICT sector, using the same intervals of variation in the number of employees in the organization. Another difference is that, when forming scenarios, only the interval of variation in the number of employees is taken into account, and almost all employees of the sector are engaged in the core activity profile. According to the data provided in Table 6 , the number of non-core employees in the ICT sector is rather few (about $0.004 \%$ ), consequently this indicator can be neglected.

Table 6

List of employees of organizations of the ICT sector(people) (2010-2015)

\begin{tabular}{|l|c|c|c|c|c|c|}
\hline \multicolumn{1}{|c|}{ Years } & 2010 & 2011 & 2012 & 2013 & 2014 & 2015 \\
\hline $\begin{array}{l}\text { List of employees of organizations } \\
\text { of the ICT sector (people) }\end{array}$ & $\mathbf{1 8 0 0 0}$ & $\mathbf{1 8 3 0 0}$ & $\mathbf{1 8 5 0 0}$ & $\mathbf{1 9 3 0 0}$ & $\mathbf{1 9 9 0 0}$ & $\mathbf{2 0 1 0 0}$ \\
\hline by core activity profile & 17932 & 18231 & 18430 & 19217 & 19824 & 20021 \\
\hline by non-core activity profile & 68 & 69 & 70 & 73 & 76 & 78 \\
\hline $\begin{array}{l}\text { proportion of non-core profile } \\
\text { employees in the total num. of } \\
\text { employees of the ICT sector } \\
\text { organizations, } \%\end{array}$ & 0,0038 & 0,0038 & 0,0039 & 0,0039 & 0,0038 & 0,0038 \\
\hline
\end{tabular}

The values of the number of IT specialists calculated in the three scenarios in the ICT sector (Table 7) show that scenario 2 provides the smallest deviation from statistical value. Therefore, in order to estimate the number of IT specialists in KEA, scenario 2 is also taken as the base.

Table 7

The estimated number of IT professionals in the ICT sector organizations with different number of employees (2015)

\begin{tabular}{|l|l|l|c|l|c|l|c|}
\hline $\begin{array}{c}\text { Number } \\
\text { of org. of } \\
\text { the ICT } \\
\text { sector }\end{array}$ & $\begin{array}{c}\text { Variation } \\
\text { interval of } \\
\text { employees }\end{array}$ & $\begin{array}{c}\text { Scen.1: } \\
\text { number of } \\
\text { employees in } \\
\text { organization }\end{array}$ & $\begin{array}{c}\text { Scen.1: } \\
\text { tot.number } \\
\text { of } \\
\text { employees }\end{array}$ & $\begin{array}{c}\text { Scenario2: } \\
\text { number of } \\
\text { employees in } \\
\text { organization }\end{array}$ & $\begin{array}{c}\text { Scen.2: } \\
\text { tot.number } \\
\text { of } \\
\text { employees }\end{array}$ & $\begin{array}{c}\text { Scen.3: } \\
\text { number of } \\
\text { employees in } \\
\text { organization }\end{array}$ & $\begin{array}{c}\text { Scen. 3: } \\
\text { tot.number } \\
\text { of } \\
\text { employees }\end{array}$ \\
\hline 264 & $1-4$ & 1 IT-prof. & 264 & 3 IT-prof. & 792 & 4 IT-prof. & 1056 \\
\hline 67 & $5-9$ & 5 IT-prof & 335 & 7 IT-prof & 481 & 9 IT-prof & 603 \\
\hline 105 & $10-49$ & 10 IT-prof & 1050 & 25 IT-prof & 2625 & 49 IT-prof & 5145 \\
\hline 78 & $50-249$ & 50 IT-prof & 3900 & 124 IT-prof & 9672 & 249 IT-prof & 19422 \\
\hline 14 & $\begin{array}{l}250 \text { and } \\
\text { more }\end{array}$ & 250 IT-prof & 3500 & 470 IT-prof & 6580 & 600 IT-prof & 8400 \\
\hline $\begin{array}{l}\text { Total number of IT } \\
\text { professionals }\end{array}$ & & $\mathbf{9 0 4 9}$ & & $\mathbf{2 0 1 5 0}$ & & $\mathbf{3 4 6 2 6}$ \\
\hline
\end{tabular}

Step 5. The calculation of the total number of IT professionals in Azerbaijan, their proportion in the ICT sector and kinds of economic activity.

At this step, it is necessary to determine the total number of IT specialists employed in the economy of Azerbaijan taking into account the conceptual scheme (Fig. 3). To calculate this indicator, we take into account: the total number of IT specialists employed in the sectors of the economy calculated according to scenario 2 (Table 4), and the number of IT specialists in the ICT sector (Table 6). Based on the results of these tables according to the formula: 


$$
P(t)_{K E A}=\sum_{i=1}^{m-1} P(t)_{K E A}^{i}+P(t)_{I C T}
$$

where $2011 \leq t \leq 2015 ; A=\left\{A_{i}, i=\overline{1, m-1} ; m=18\right\}$ is the quantity of KEA. The calculation of the total number of IT professionals employed in the sectors of the economy (excluding the ICT sector) and in the ICT sector. This allows to find the proportion of IT professionals by the ICT sector and, correspondingly, in other sectors of the economy by the following formula:

$$
d(t)_{I C T}=\frac{P(t)_{I C T}}{P(t)_{K E A}} \times 100
$$

Table 8 shows the distribution of the total number of IT professionals employed in the economy of Azerbaijan $\left(P(t)_{K E A}\right)$, in the ICT sector $\left(P(t)_{I C T} ; d(t)_{I C T}\right)$ and other economic $\operatorname{activities}\left(\sum_{i=1}^{m-1} P(t)_{K E A}^{i} ; d(t)_{K E A}\right)$.

Table 8

The total number of IT professionals employed in the economy of Azerbaijan and its distribution in the ICT sector and other economic activities

\begin{tabular}{|c|c|c|c|c|c|}
\hline Year & $P(t)_{I C T}$ & $\sum_{i=1}^{m-1} P(t)_{K E A}^{i}$ & $P(t)_{K E A}$ & $\begin{array}{c}\text { Specific weight of } \\
\text { IT-spec. in the ICT } \\
\text { sector, \% }-d(t)_{I C T}\end{array}$ & $\begin{array}{c}\text { Specific weight of } \\
\text { IT-spec. in KEA, \% - } \\
d(t)_{K E A}\end{array}$ \\
\hline 2011 & 18300 & 28374 & 46674 & 36,9 & 63,1 \\
\hline 2012 & 18500 & 31092 & 49592 & 37,3 & 62,7 \\
\hline 2013 & 19300 & 33602 & 52902 & 36,4 & 63,6 \\
\hline 2014 & 19900 & 34995 & 54895 & 36,2 & 63,8 \\
\hline 2015 & 20100 & 35871 & 55971 & 35,9 & 64,1 \\
\hline
\end{tabular}

\section{Conclusion}

The total number of IT professionals employed in the economy of Azerbaijan, and their distribution in the ICT sector and other KEA annually for 2011-2015 showed that the majority of IT professionals work beyond the ICT sector. This indicates that IT professionals in Azerbaijan are mostly "absorbed" by other areas of the economy, i.e. the expansion of the IT market is mainly due to other KEA. The formation of the basic demand for IT specialists in the economic sectors is a logical result of the policy of state support for the ICT sector in Azerbaijan. The transformation of the latter into a catalyst for the development of an innovative economy and information society in the country is also included to this process. The realization of ambitious plans for the informatization of various spheres of human activity in Azerbaijan, in accordance with the adopted political documents [9-11], is estimated to contribute to the further changes in the obtained percentage of the number of IT specialists in favor of the national economy.

The ability to effectively assess the demand for IT specialists in the national context will facilitate the adoption of more informed management decisions to bring the training system of IT-specialists in line with the requirements of the national economy. 


\section{References}

1. Mammadova M.G., Mammadzada F.R. Conceptual Approaches to the Intellectual Management of the IT Labor Market // Problems of Information Technologies, Baku, No. 2 (8), 2013, pp.33-44. http://jpit.az/storage/files/article/4c6a7d96.pdf

2. Mammadova M.G., Mammadzada F.R. Object-oriented approach to the determination of the relevance of information technology education to the demand in the market of IT professionals / / Education and Science, Moscow, No 5, 2014, pp.54-67.

3. Didero M., HusingT., Korte W.B. Monitoring e-Skills demand and supply in Europe: Synthesis report The evolution of the supply and demand of e-Skills in Europe. European Commission, 2009, 58 p. http://staging.ilo.org/public/libdoc/ igo/2009.pdf

4. Research Study on High-Level Skill Needs in NIICT Sector. Final Report. Oxford Economics, 2009, 129 p. http://dera.ioe.ac.uk/10639/1/research_study_final_report.pdf

5. Hüsing T., Korte W., Dashja E. e-Skills in Europe. Trends and Forecasts for the European ICT Professional and Digital Leadership Labour Markets (2015-2020). Working Paper, 2015, 42 p. http://eskills-ead.eu/fileadmin/lead/working_paper_su.pdf

6. IT staff-2010. The number of employees in the Russian economy in 2009 and the demand forecast for 2010-2015. Analytical study of the REAL-IT center on the initiative of AP KIT, 2010, 24 p.

7. Information society. Main indicators of ICT infrastructure. http://stat.gov.az/source/information_society/

8. Mammadova M.H., Jabrayilova Z., Manafli M.I. Monitoring of the demand for IT specialists. Baku: Information Technologies, 2009, 199 p.

9. Concept of Development Azerbaijan 2020: Look into the Future. Decree of the President of the Republic of Azerbaijan of December 29, 2012 http://president.az/files/future_az.pdf

10. National Strategy for Information Society Development in the Republic of Azerbaijan for 2014-2020. Order of the President of the Republic of Azerbaijan dated April 2, 2014 http://president.az/articles/11312.

11. Strategic Roadmap for the Development of Telecommunications and Information Technology. Decree of the President of the Republic of Azerbaijan dated December 6, 2016. http://president.az/articles/22382 